\title{
Coupled climate model simulations of Mediterranean winter cyclones and large-scale flow patterns
}

\author{
B. Ziv ${ }^{1}$, Y. Kushnir ${ }^{2}$, J. Nakamura ${ }^{2}$, N. H. Naik ${ }^{2}$, and T. Harpaz ${ }^{1}$ \\ ${ }^{1}$ Department of Natural Sciences, The Open University of Israel, Israel \\ ${ }^{2}$ Lamont-Doherty Earth Observatory, The Earth Institute, Columbia University, New York, USA
}

Correspondence to: B. Ziv (baruchz@openu.ac.il)

Received: 23 April 2012 - Published in Nat. Hazards Earth Syst. Sci. Discuss.: -

Revised: 11 February 2013 - Accepted: 12 February 2013 - Published: 26 March 2013

\begin{abstract}
The study aims to evaluate the ability of global, coupled climate models to reproduce the synoptic regime of the Mediterranean Basin. The output of simulations of the 9 models included in the IPCC CMIP3 effort is compared to the NCEP-NCAR reanalyzed data for the period 19611990. The study examined the spatial distribution of cyclone occurrence, the mean Mediterranean upper- and lower-level troughs, the inter-annual variation and trend in the occurrence of the Mediterranean cyclones, and the main largescale circulation patterns, represented by rotated EOFs of $500 \mathrm{hPa}$ and sea level pressure.

The models reproduce successfully the two maxima in cyclone density in the Mediterranean and their locations, the location of the average upper- and lower-level troughs, the relative inter-annual variation in cyclone occurrences and the structure of the four leading large scale EOFs. The main discrepancy is the models' underestimation of the cyclone density in the Mediterranean, especially in its western part. The models' skill in reproducing the cyclone distribution is found correlated with their spatial resolution, especially in the vertical. The current improvement in model spatial resolution suggests that their ability to reproduce the Mediterranean cyclones would be improved as well.
\end{abstract}

\section{Introduction}

Instrumental precipitation records indicate that in recent decades much of the land area surrounding the Mediterranean Basin (MB) has experienced a decline in winter season precipitation (e.g. Dunkeloh and Jacobeit, 2003). According to the models included in the IPCC Fourth
Assessment (IPCC, 2007; Giorgi and Lionello, 2008; Mariotti et al., 2008), this region is expected to experience a $10-20 \%$ drop in precipitation toward the end of the 21 st century. This expectation is critical for the Mediterranean countries due to their dense population and rich agricultural resources (see Iglesias et al., 2007).

The prime contributors to the precipitation in the $\mathrm{MB}$ are migrating wintertime extratropical cyclones (e.g. Hertig and Jacobeit, 2008; Lionello, 2012). The linkage between Mediterranean cyclones (hereafter MCs) and precipitation is also addressed by Trigo et al. (2000), who attributed the observed negative precipitation trend to a decline in the frequency of severe storms entering the Mediterranean from the west and northwest. The relationship between the MCs and precipitation is demonstrated here by the correlation between the time series of the seasonal number of cyclones and precipitation in 38 winter seasons (December-February), shown in Fig. 1 (for details regarding the analysis of cyclone counts, see Sect. 3.1). Since the temporal correlation is based on 38 winter seasons, values exceeding 0.27 are significant at the 0.95 level. The correlation is thus significant over much of the MB. The above implies that the observed and projected trend in precipitation in the Mediterranean is linked to trend in the occurrence of MCs. This relationship and the additional importance of MCs as a source of extreme weather events (associated with wind storms, dust events, temperature extremes, etc.) make them an important target of investigation (e.g. Frich et al., 2002; Xoplaki et al., 2004; Lionello et al., 2006; Raible, 2007).

A pioneering attempt to assess the future change in the synoptic regimes over the MB was done by Lionello et al. (2002), using the ECHAM4 model with T106 resolution 


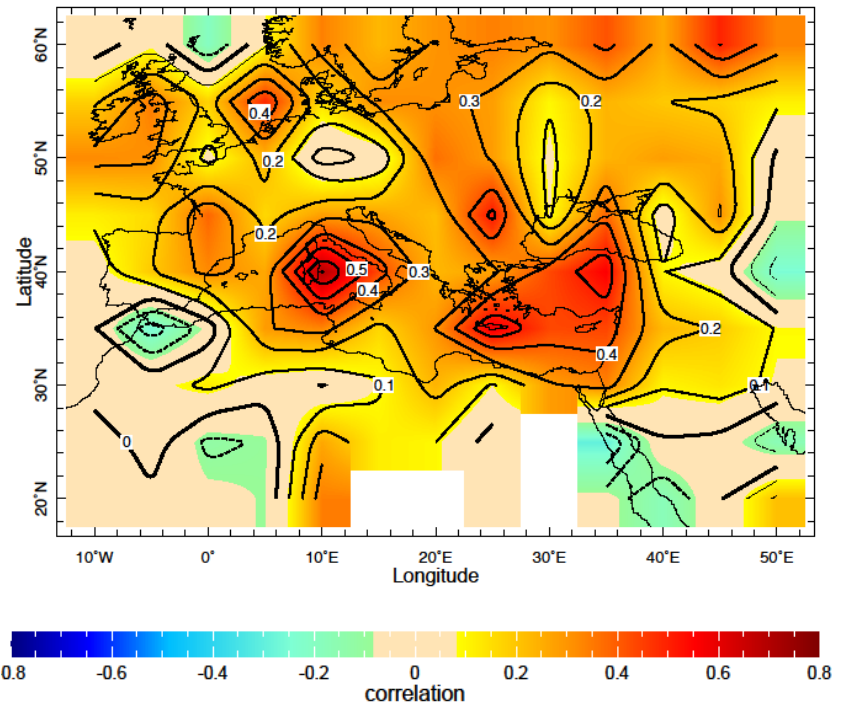

Fig. 1. Correlation, calculated for each grid cell of $5^{\circ} \times 5^{\circ}$, between the time series of DJF rainfall and cyclone counts. The cyclones were extracted from the sea level pressure daily fields of the NCEPNCAR reanalysis project (Kalnay et al., 1996; Kistler et al., 2001). The methodology for cyclones' detection is described in Sect. 3.1 and the rainfall is taken from the NOAA/NCEP CAMS data set (Ropelewski et al., 1984; Janowiak and Xie, 1999), which relies on observations. Correlations higher than 0.27 indicate 0.95 significance.

(about $1.1^{\circ} \times 1.1^{\circ}$ ). They compared 30-yr model integration with the present conditions to a parallel one with a doubled $\mathrm{CO}_{2}$ concentration. They did not find substantial differences between the two, except for an insignificant tendency for increase in the number of deepest cyclones (measured in pressure difference between the center and the periphery of the cyclone) and some decrease in the occurrences of less deep systems. Bengtsson et al. (2006) conducted a study of global cyclogenesis and cyclone tracks in the present and in the projected changes under the so-called A1B emission scenario (Nakicenovic et al., 2000). They analyzed output from the ECHAM5 coupled model, in the version used during the IPCC Fourth Assessment (AR4), and found the greenhouse gas forced the 21 st century simulation to exhibit a marked decrease in cyclone activity and intensity in the MB during winter. Giorgi and Lionello (2008), using ensembles of global and regional models, attributed the expected future decrease in rainfall to a development of a general anticyclonic circulation over the Mediterranean, seen in their average difference maps (future minus present) of both the sea level pressure (slp) and upper-level geopotential height (gph). Lionello and Giorgi (2007) also compared the future changes in precipitation and in cyclone occurrences, using a regional model (of $50 \mathrm{~km}$ resolution) with boundary conditions from the HadAM $3 \mathrm{~h}$ model with $1.25^{\circ} \times 1.875^{\circ}$ resolution and for the IPCC AR4 A2 and B2 scenarios (IPCC, 2007). They found agreement between the change in precipitation and in the occurrence of intense cyclones (which are at least $15 \mathrm{hPa}$ deep compared to their surrounding), expressed by a decrease over the majority of the MB and an increase along its northern coasts and further north in Europe.

In assessment of future climate projection of climate, it is common to use information from several models to draw conclusions that are more robust than when using a single model (counting on the multi-model analysis to reduce the effect of model biases and increasing the data sample when separating the effect of externally forced changes from internal variability). When selecting models, it is reasonable to assume that models that offer a more realistic simulation of the present climate are more reliable than others (Reichler and Kim, 2008). The studies mentioned above contributed to the evaluation of climate model reliability in reproducing recent (late 20th century) synoptic conditions. Bengtsson et al. (2006) found that the model (ECHAM5), viewed from a global perspective, simulates recent (1979-2002) observed cyclone activity quite well. Lionello and Gorgi (2007) found that the regional model they used provides a good agreement between the distribution pattern of intense cyclones (deeper than $15 \mathrm{hPa}$ ) over Europe and the MB, except for a maximum found over eastern Turkey in the model's output but not in the data (ERA-40). Raible et al. (2010) examined the ability of the ECHAM5 model, in a more advanced version than that used in the IPCC AR4 (IPCC, 2007), i.e. with a horizontal resolution of $1.125 \times 1.125$ and 31 hybrid sigma pressure levels, to reproduce synoptic features of the MB and Europe. They showed that the simulated general pattern of cyclone density is quite realistic over both regions, but that their density over the Mediterranean is underestimated.

In the present study we evaluate the ability of 9 different AR4 models to reproduce the present winter synoptic features of the MB, in particular the cyclonic activity. Our study compares the output of a multi-model ensemble and the observations, and also looks into differences among the models in an attempt to discern the factos behind more successful simulations of the observations. The 9 models were those used in the simulations of the 20th century during the World Climate Research Program (WCRP) Third Couple Model Inter-comparison Project (CMIP3, Meehl et al., 2007) - a project that was an integral part of the IPCC AR4 (IPCC, 2007). In addition to studying the pattern of surface cyclone counts and their inter-annual variation, we examine the largescale circulation mean and variability. Specifically, we examine the climatological mean slp and 500-hPa gph fields, the intensity and location of the mean Mediterranean trough (Jacobeit, 1987) and the typical patterns of inter-annual wintertime 500-hPa gph (and of slp) variability.

The plan of the paper is as follows: Sect. 2 provides information on the data used in this study. Section 3 describes the methods of analysis. Section 4 presents the results and Sect. 5 is a summary and discussion. 


\section{Data}

The study deals with the boreal winter season, i.e. the months of December through February (DJF), which form the core of the Mediterranean rainy season. The study period is $1961-$ 1999 and contains 38 winters. The study region is $20^{\circ}-70^{\circ} \mathrm{N}$, $30^{\circ} \mathrm{W}-60^{\circ} \mathrm{E}$.

The data available for the observational basis is the NCEP-NCAR reanalysis project, with a $2.5^{\circ} \times 2.5^{\circ}$ resolution (Kalnay et al., 1996; Kistler et al., 2001), serve here to represent the observed conditions (referred to as "observations", hereafter). As indicated in the introduction, the simulated data are derived from the output of 9 CMIP3 models, which provide daily mean resolved output. These data are from the Program for Climate Model Diagnostics and Intercomparisons (PCMDI) at the Lawrence Livermore National Laboratory (see http://www-pcmdi.llnl.gov/ipcc/about_ipcc. php) and are referred to as "simulations" hereafter. The observed and simulated cyclone statistics are calculated using daily slp fields (see further details in Sects. 3.1 and 3.2 below). The spatial resolution of the NCEP-NCAR reanalyzed data is $2.5^{\circ} \times 2.5^{\circ}$, which is appropriate for analysis of synoptic-scale features and is compatible with that of the studied models (see Table 1), though finer resolution is generally better for cyclone analysis (e.g. for explosive cyclogenesis, as shown by Kouroutzoglou et al., 2011). Other atmospheric circulation properties were calculated from the monthly-mean output of the same sources. A brief list of the study model properties is given in Table 1 (for further details regarding these models see Randall et al., 2007).

For the observed precipitation we used the NOAA/NCEP CAMS dataset, which provides monthly compilations derived from land-based rain gauge measurements (Ropelewski et al., 1984; Janowiak and Xie, 1999). These data are in $2^{\circ} \times 2^{\circ}$ spatial resolution.

\section{Methods}

\subsection{Cyclone detection}

The cyclone detection algorithm applied here is based on the one used by Raible and Blender (2004), Raible et al. (2008, 2010). The algorithm was applied to daily slp fields of the observations and simulations. Prior to the detection process the data were interpolated from their original spatial resolution (which varied from one model to another) to a $2.5^{\circ} \times 2.5^{\circ}$ latitude by longitude grid (identical to that of the observations) to bring both simulations and observations to a common resolution. Next, the data resolution was refined by performing spline interpolation to a finer $0.5^{\circ} \times 0.5^{\circ}$ grid in order to increase the accuracy in locating the identified lowpressure centers (following Pinto et al., 2005) and to derive more accurately the gradient around them for final selection of cyclones to be included. However, this procedure can be viewed largely as a technical step, does not add any cyclones to those found in the original data and hence has no impact on the results.

A screening of the analysis region for local minima then follows. A candidate cyclone center is a local slp minimum with respect to its surrounding 8 grid points at the corners and the sides of a $5^{\circ} \times 5^{\circ}$ grid box centered on the pertinent gridpoint, provided that the minimum value is lower by at least $4 \mathrm{hPa}$ than the average value of all the surrounding 8 gridpoints.

Inspection of 3 months of data showed that the above criteria were met not only for closed cyclones, but in several cases also for open troughs, which had no real minimum (except the one associated with the remote, often outside the study region, low-pressure center from which the trough extends). To avoid this problem we added an additional criterion to the detection algorithm, which examines the pressure difference between the minimum point and each of its 8 neighboring $2.5^{\circ}$ grid points. We identified a trough (and not a closed cyclone) when the pressure gradient in one direction was lower than $4 \mathrm{~Pa} / 1^{\circ}$ while in the opposite direction it exceeds it. This threshold was obtained through several iterations until optimum agreement between the distributions of the cyclones detected manually by trained forecasters and these detected automatically through our algorithm was achieved.

\subsection{Representativeness of daily averages for cyclone detection}

The analysis of MCs is based on daily-averaged slp. It is important to verify whether such sampling resolution is sufficient for detecting the migrating wintertime cyclones and their climatological distribution. The analysis of $24 \mathrm{~h}$ resolution data is expected to underestimate the number of cyclones found in higher temporal resolution data, especially when they move fast. For that reason the cyclone detection program was applied first to the output of the GFDL-cm2.1 model, for which 3-hourly data were available for $10 \mathrm{yr}$, in $24 \mathrm{~h}$ intervals, as well as daily averaged data. Results for randomly selected 3 boreal fall seasons (October-November), winters (DJF) and spring seasons (March-April) were compared within the domain $20^{\circ}$ to $70^{\circ} \mathrm{N}$ and $20^{\circ} \mathrm{W}$ to $55^{\circ} \mathrm{E}$.

As expected, the number of cyclones found in the instantaneous data is consistently larger than that found in the daily averaged ones. However, the ratio between the two counts remained stable, in the range of $0.83-0.92$ for all the 9 seasons examined. These ratios are considerably larger than the 0.53 ratio obtained by Blender and Schubert (2000), presumably due to the difference in the study region they used and that used here. The area studied by Blender and Schubert (2000) covers the Northern Hemisphere north of $40^{\circ} \mathrm{N}$, so that the MCs are a negligibly small portion of their sample, whereas in the present study they are the majority. The slow movement of the MCs, with a typical speed of $5-10 \mathrm{~m} \mathrm{~s}^{-1}$ (Alpert and $\mathrm{Ziv}, 1989$ ), implies that the $24 \mathrm{~h}$ resolution data would 
Table 1. The study models and their main characteristics.

\begin{tabular}{|c|c|c|c|}
\hline Model & Source & $\begin{array}{l}\text { Horizontal } \\
\text { resolution }\end{array}$ & $\begin{array}{c}\text { Number of } \\
\text { vertical levels }\end{array}$ \\
\hline GFDL-cm2.0 & $\begin{array}{l}\text { US Department of Commerce/NOAA/Geophysical Fluid Dynamics } \\
\text { Laboratory, USA }\end{array}$ & $2.0^{\circ} \times 2.5^{\circ}$ & 24 \\
\hline GFDL-cm 2.1 & $\begin{array}{l}\text { US Department of Commerce/NOAA/Geophysical Fluid Dynamics } \\
\text { Laboratory, USA }\end{array}$ & $2.0^{\circ} \times 2.5^{\circ}$ & 24 \\
\hline NCAR CCSM3.0 & National Center for Atmospheric Research, USA & $\mathrm{T} 85\left(1.4^{\circ} \times 1.4^{\circ}\right)$ & 26 \\
\hline MIROC3 HiRes & $\begin{array}{l}\text { Center for Climate System Research (University of Tokyo), Na- } \\
\text { tional Institute for Environmental Studies and Frontier Research } \\
\text { Center for Global Change, Japan }\end{array}$ & $\mathrm{T} 106\left(1.1^{\circ} \times 1.1^{\circ}\right)$ & 56 \\
\hline MIROC3 MedRes & $\begin{array}{l}\text { Center for climate system research (University of Tokyo), National } \\
\text { Institute for Environmental Studies and Frontier Research Center } \\
\text { for Global Change, Japan }\end{array}$ & $\mathrm{T} 42\left(2.8^{\circ} \times 2.8^{\circ}\right)$ & 20 \\
\hline INGV ECHAM 4 & Italy & $\mathrm{T} 63\left(1.9^{\circ} \times 1.9^{\circ}\right)$ & 21 \\
\hline MPI ECHAM 5 & Max Plank Institute for Meteorology, Germany & $\mathrm{T} 63\left(1.9^{\circ} \times 1.9^{\circ}\right)$ & 31 \\
\hline CSIRO-mk3.0 (2 runs) & $\begin{array}{l}\text { Commonwealth Scientific and Industrial Research Organization, } \\
\text { Marine and Atmospheric Research, Australia }\end{array}$ & $\operatorname{T} 63\left(1.9^{\circ} \times 1.9^{\circ}\right)$ & 18 \\
\hline CSIRO-mk3.5 & $\begin{array}{l}\text { Commonwealth Scientific and Industrial Research Organization, } \\
\text { Marine and Atmospheric Research, Australia }\end{array}$ & $\mathrm{T} 63\left(1.9^{\circ} \times 1.9^{\circ}\right)$ & 18 \\
\hline
\end{tabular}

capture a larger portion of them than it may for the Atlantic and European cyclones. The spatial correlation between the density distributions of cyclone counts extracted from the two output types was used to estimate the representativeness of the $24 \mathrm{~h}$ resolution data for the data having $3 \mathrm{~h}$ resolution. The correlation varied between 0.76 and 0.93 . The stable ratio and the high spatial correlation between the two sets indicate that the use of daily averages is appropriate for the purpose of our analysis and is capable of providing useful statistics for model-observations and model-model comparisons.

\subsection{EOF analysis}

The models ensemble's ability to simulate the observed patterns of inter-annual variability was examined for the winter season averaged 500-hPa gph to a principal component analysis (PCA a.k.a EOF analysis) over the entire study area. The spatial patterns of such an analysis (hereafter EOF patterns) tend to be sensitive to sampling fluctuations and the choice of the study domain (e.g. North et al., 1982), and might affect an attempt to compare the models to one another and to observations. Thus we proceeded to apply a "factor rotation" procedure to the PCA results. Such an additional step has been shown to yield much more stable patterns in relatively short data samples (Cheng et al., 1995). Here we applied a VARIMAX rotation procedure (Cheng et al., 1995) to the leading five PCs of each model and of the observations. The choice of the number of PCs was based on Rule N, a test for EOF variance separation, based on the normalized EOF variance and a standard error thereof, derived from parametric considerations (North et al., 1982; Preisendorfer, 1988).
The collective ability of the models to simulate the observed patterns of DJF $500 \mathrm{hPa}$ gph variability was done by gathering the individual 342 observations, i.e. $38 \mathrm{yr}$ of 9 models, for extracting the simulated EOFs. This approach is sometimes referred to as "the common EOF method" (e.g. Barnett, 1999).

\section{Results}

\subsection{Mediterranean cyclones - spatial distribution}

The analysis of MCs was performed for the region bounded by the longitudes of $10^{\circ} \mathrm{W}$ and $50^{\circ} \mathrm{E}$ and the latitudes of $20^{\circ} \mathrm{N}$ and $60^{\circ} \mathrm{N}$ (referred to as the "larger MB" hereafter). The climatological spatial distribution of daily cyclone counts per winter, December through February (DJF), based on data of 1961/1962-1998/1989, in a resolution of $5^{\circ} \times 5^{\circ}$ (an area of approximately $2.5 \times 10^{6} \mathrm{~km}^{2}$ ), is shown in Fig. 2 . The prominent two maxima within the Mediterranean Basin, at $40^{\circ} \mathrm{N}$ and $11^{\circ} \mathrm{E}$ and at $35^{\circ} \mathrm{N}$ and $30^{\circ} \mathrm{E}$, reflect the tendency of cyclones to concentrate mainly in two areas: one in the western basin, near Italy, and the other in the eastern basin, south of the southern coast of Turkey. The maximum values within these centers are 5-6 cyclone centers per $5^{\circ} \times 5^{\circ}$ grid box per season. The distribution of cyclone counts over southern Europe is rather uniform, varying between 1.5 and 2 cyclone centers per $5^{\circ} \times 5^{\circ}$ grid box per season, increasing northward towards the location of the European storm track.

The higher cyclone density over the MB compared to that over central Europe agrees with previous studies such as that by Pinto et al. (2005) and Ulbrich et al. (2009). However, the 


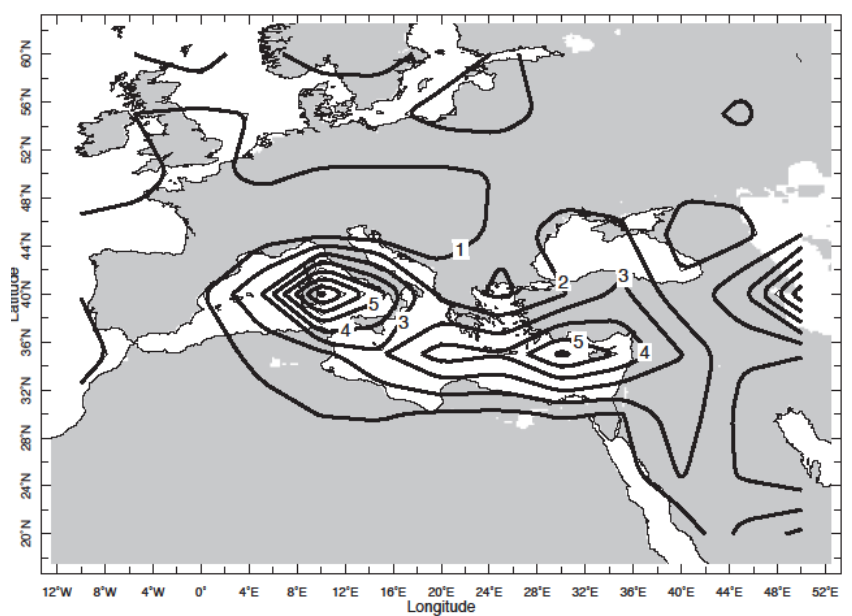

Fig. 2. Observed average number of wintertime (DJF) cyclones in a $5^{\circ} \times 5^{\circ}$ grid boxes (in counts per box per year, in 1.0 interval) derived from the NCEP-NCAR Reanalysis daily averaged sea level pressure fields from 38 winters between 1961/1962 and 1998/1999.

low counts seen over Europe may be partly attributed to the use of daily averaged output, which underestimate cyclones' occurrence in regions where they move relatively fast, such as Europe, in contrast to the Mediterranean, where they tend to be slow, particularly near cyclogenetic centers. This uniform distribution over Europe stands in contrast to the highly variable distribution of MCs, emphasizing the cyclogenetic character of the Mediterranean and hints at the role of the geography of the Mediterranean Basin (i.e. land-sea contrast and location of mountain ridges) in the cyclogenesis process (e.g. Tafferner and Egger, 1989; Alpert et al., 1996; Trigo et al., 2002). The pattern seen in Fig. 2 is substantially different from that found by Lionello and Giorgi (2007, see their Fig. 4), where one maximum over Europe and a secondary one over the Adriatic Sea were detected. This difference is most likely the result of the threshold for cyclone depth used in their study for isolating deep cyclones $(15 \mathrm{hPa}$ compared to $4 \mathrm{hPa}$ here).

Table 2 shows the total number of cyclones detected in the simulations and observations over the larger MB. Also shown are the percentages of cyclones found in the West Mediterranean (WM, $\left.35^{\circ} \mathrm{N}-45^{\circ} \mathrm{N}, 5^{\circ} \mathrm{E}-20^{\circ} \mathrm{E}\right)$ and the East Mediterranean $\left(\mathrm{EM}, 30^{\circ} \mathrm{N}-40^{\circ} \mathrm{N}, 25^{\circ} \mathrm{E}-40^{\circ} \mathrm{E}\right.$ ) out of the total number of cyclones over the "larger MB", their average intensity and minimum slp value in each of these regions. The intensity of a cyclone is represented by the pressure difference between its center and the average over the 8 grid points at the corners and the sides of a $5^{\circ} \times 5^{\circ}$ grid box around it. The most striking feature seen in Table 2 is the large differences among the various models and between models and observations in the number of cyclones detected in the study area. The number of simulated cyclone counts in the larger MB area varies from 3239 for the GFDL-cm2.0 to 7824 for

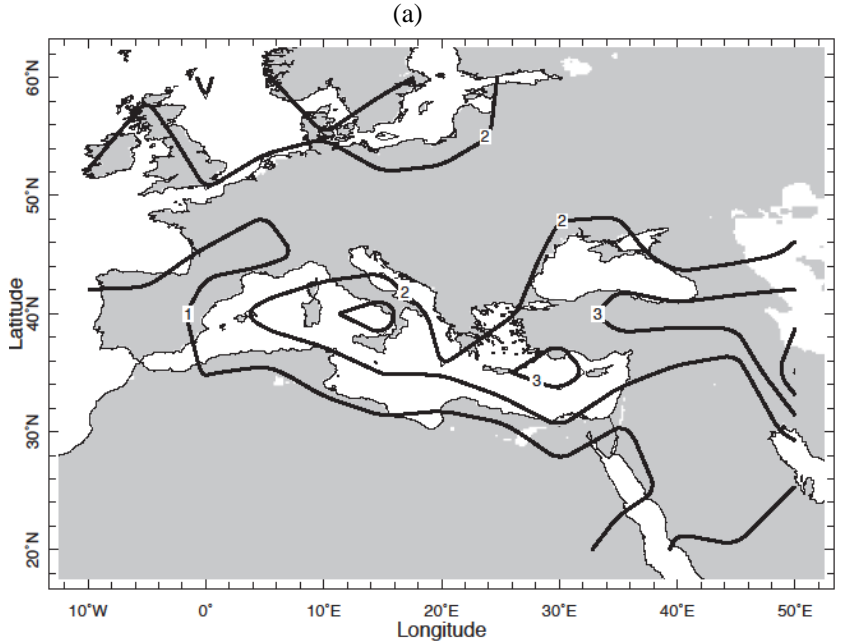

(b)

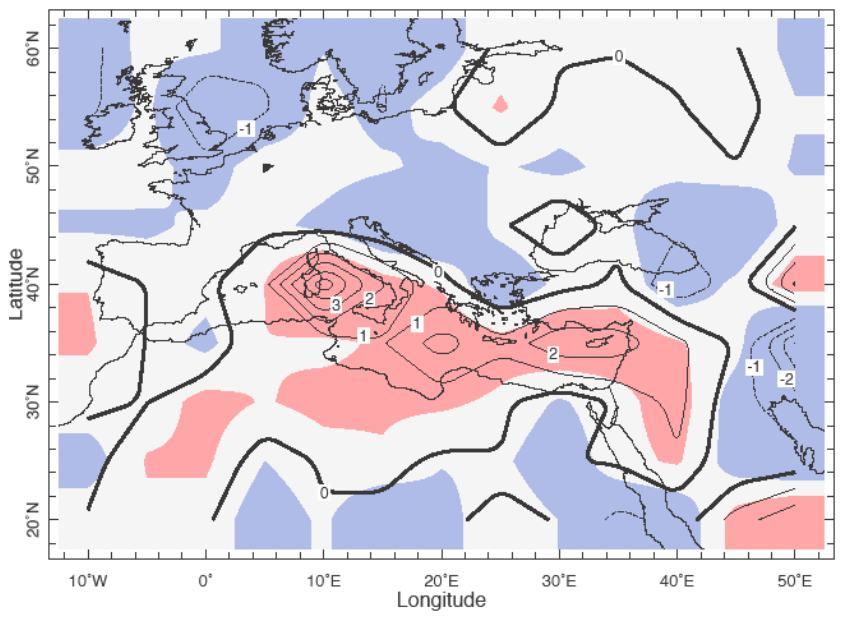

Fig. 3. (a) As for Fig. 2, but averaged over the 9 study models. The counts of each model are normalized by the ratio between its total number of detected cyclones and that detected in the observations. (b) The difference between the observed and model-averaged (Figs. 2 and 3a, respectively). The contours are in 1.0 interval and the zero line is thick. The t-test is a "Welch t-test", which accounts for the different variance in the observations and models. The models are pooled together and normalized, as explained in the test. The colors indicate regions in which the difference is significant at the level of $95 \%$ based on an estimate of 40 degrees of freedom; pale pink indicates significant model under-estimation and pale blue indicates significant model over-estimation.

the CSIRO-mk3.0, and the multi-model average number of cyclones exceeds that based on the observations by $67 \%$.

One might speculate that this discrepancy is related to differences in model resolution, but we found no systematic relationship between these factors. Moreover, the number of cyclone counts obtained by the model with the highest resolution, MIROC3 HiRes, was far from having the highest number of cyclone counts (4 models had more counts), and was lower than that obtained for the MIROC3 MedRes, 
Table 2. Features of the cyclone occurrence statistics in the Mediterranean Basin. The methodology for cyclone detection is described in Sect. 3.1. The intensity of a cyclone is represented by the pressure difference between its center and the average over the 8 grid points at the corners and the sides of a $5^{\circ} \times 5^{\circ}$ grid box around it. Note that the percentages (columns 5 and 8 ) are defined with respect to the "large MB" $\left(10^{\circ} \mathrm{W}-50^{\circ} \mathrm{E}, 20^{\circ}-60^{\circ} \mathrm{N}\right)$, so they are not summed to 100 .

\begin{tabular}{|c|c|c|c|c|c|c|c|}
\hline \multirow{2}{*}{ Source } & \multirow[b]{2}{*}{$\begin{array}{r}\text { Total No. } \\
\text { of cyclones }\end{array}$} & \multicolumn{3}{|c|}{ East Mediterranean } & \multicolumn{3}{|c|}{ West Mediterranean } \\
\hline & & $\begin{array}{r}\text { Average central } \\
\operatorname{slp}(\mathrm{hPa})\end{array}$ & $\begin{array}{r}\text { Ave intensity } \\
(\mathrm{hPa})\end{array}$ & $\begin{array}{r}\text { Percentage } \\
(\%)\end{array}$ & $\begin{array}{l}\text { Average min. } \\
\quad \operatorname{slp}(\mathrm{hPa})\end{array}$ & $\begin{array}{r}\text { Ave intensity } \\
(\mathrm{hPa})\end{array}$ & $\begin{array}{r}\text { Percentage } \\
(\%)\end{array}$ \\
\hline Observations & 3372 & 1009.2 & 7.3 & 19.0 & 1006.8 & 7.8 & 18.8 \\
\hline GFDL-cm 2.0 & 3239 & 1011.7 & 8.4 & 13.6 & 1006.3 & 9.2 & 14.2 \\
\hline GFDL-cm 2.1 & 3852 & 1013.0 & 8.0 & 16.0 & 1009.1 & 9.5 & 11.5 \\
\hline NCAR ccsm3.0 & 4475 & 1011.9 & 9.5 & 16.0 & 1007.5 & 10.7 & 10.1 \\
\hline MIROC3 HiRes & 6347 & 1011.7 & 7.8 & 17.9 & 1006.8 & 9.5 & 15.0 \\
\hline MIROC3 MedRes & 6863 & 1010.0 & 6.8 & 14.8 & 1008.2 & 7.4 & 12.4 \\
\hline ECHAM4 & 6465 & 1013.7 & 7.9 & 16.6 & 1011.0 & 9.5 & 11.4 \\
\hline ECHAM5 & 5597 & 1011.6 & 7.7 & 19.7 & 1006.2 & 9.2 & 12.9 \\
\hline CSIRO-mk3.0, run 1 & 7824 & 1014.3 & 7.7 & 12.8 & 1009.6 & 9.6 & 12.5 \\
\hline CSIRO-mk3.0, run2 & 6779 & 1014.7 & 8.7 & 14.9 & 1006.3 & 11.3 & 10.4 \\
\hline CSIRO-mk3.5 & 4769 & 1013.6 & 7.7 & 11.6 & 1003.7 & 11.8 & 10.4 \\
\hline Model average & 5621 & 1012.6 & 8.0 & 15.4 & 1007.5 & 9.8 & 12.1 \\
\hline Models minus Observations & 2249 & 3.4 & 0.8 & -3.6 & 0.7 & 1.9 & -6.7 \\
\hline Deviation $(\%)$ & 67 & 0.3 & 11 & 19 & 0.1 & 24 & 36 \\
\hline
\end{tabular}

which has the coarsest resolution among the study models. Previous studies examined the relationship between the model resolution and the number of cyclones detected in the output fields. Blender and Schubert (2000) and Zolina and Gulev (2002) found that the number of detected cyclones for a certain model increases when its horizontal resolution is enhanced. However, their studies used the same model and varied the threshold for truncation of its output data, whereas this study compares different models with their native spatial resolution. Therefore there is no real disagreement between the relationship they found and the lack of such in our study.

The percentage of cyclones found within the cyclogenetic centers in the Mediterranean reflect both the relative cyclone density between the west (WM) and east Mediterranean (EM) as well as the relative density over the Mediterranean as a whole with respect to Europe. Table 2 shows that the models underestimate the relative number of cyclone occurrences in both the WM and EM. In the EM they display a range from $19.0 \%$ in the observations to $15.4 \%$ in the simulations, and in the WM the discrepancy is larger: from $18.8 \%$ in the observations to $12.1 \%$ in the simulations. The average minimum pressure in the cyclone centers is lower in the observations than in the simulations, by $3.4 \mathrm{hPa}$ for the EM and 0.7 for the WM. The intensity of the cyclones was overestimated by the models for both regions, by $11 \%$ and $24 \%$ for the EM and WM, respectively.

Figure $3 \mathrm{a}$ and $\mathrm{b}$ show the distribution of cyclone occurrence averaged over the 9 models and the difference between the average simulated and the observed, respectively. The cyclone distribution of each model is normalized by the ratio between its total number of cyclone counts and that of observation (both shown in the left panel in Table 2). The results for the individual models, together with the standard model errors (the root-mean-square differences between model and observations averaged over the large MB) are listed in Table 3 (see also Sect. 5). These standard errors vary between 0.31 (for the MIROC3 HiRes) and 0.56 (for the CSIROmk3.5). A comparison between the average simulated cyclone distribution pattern and the observed pattern (Figs. 3b and 2 , respectively) indicates that the models overestimate the relative cyclone occurrences over Europe and underestimate it in the Mediterranean. While the difference over Europe is not significant everywhere, in the MB it is significant. The underestimation of cyclone density is more pronounced in the WM (see also Table 2). According to the models, it appears as if a larger part of the Atlantic cyclones that enter Europe remain over the continent and a smaller portion of them enters (or forms secondary cyclones) in the Mediterranean than is found in nature (for more details, see Romem et al., 2007).

There are two factors which may contribute to underestimation of the MC density with respect to the European cyclones: one is the bias resulting from our density definition, given in terms of number of cyclones per grid cell (of $5^{\circ} \times 5^{\circ}$ ); the areal density is underestimated proportionally to cosine (lat). Second is the smoothing out of fast moving cyclones in the $24 \mathrm{~h}$ time resolution data (see also Sect. 3.2), which is expected to affect especially the European cyclones, which are faster than the MCs. However, these effects do not affect the comparison between observation and simulation. 
Table 3. List of quantitative estimates for the ability of the 9 study models to reproduce the observed synoptic features. The results for the 3 models with the highest score in each category are indicated in bold letters. Note that for all of the estimates, excluding the Average Cyclone counts relative inter-annual STD and the rotated EOF coherence, smaller values reflect better performance.

\begin{tabular}{lrrrrr}
\hline Model & $\begin{array}{r}\text { Cyclone } \\
\text { distribution Standard } \\
\text { error }\end{array}$ & $\begin{array}{r}\text { Average Cyclone } \\
\text { counts relative } \\
\text { inter-annual STD }\end{array}$ & $\begin{array}{r}\text { SNI } \\
\text { (defined in } \\
\text { Sect. 4.3) }\end{array}$ & $\begin{array}{r}\text { (zonal anomaly) } \\
\text { Standard error }\end{array}$ & $\begin{array}{r}\text { Rotated } \\
\text { EOF } \\
\text { Coherence }\end{array}$ \\
\hline GFDL-cm2.0 & 0.44 & $\mathbf{1 . 0 8}$ & $\mathbf{1 . 7}$ & 32 & 2.10 \\
GFDL-cm2.1 & 0.45 & $\mathbf{1}$ & 2.1 & 32 & $\mathbf{2 . 9 8}$ \\
NCAR ccsm3.0 & 0.44 & $\mathbf{1 . 0 2}$ & 3.6 & 28 & 2.25 \\
MIROC3 HiRes & $\mathbf{0 . 3 1}$ & 0.99 & $\mathbf{1 . 6}$ & $\mathbf{1 9}$ & 2.08 \\
MIROC3 MedRes & 0.55 & 0.9 & 2.3 & 26 & $\mathbf{3 . 1 6}$ \\
ECHAM4 & $\mathbf{0 . 4 2}$ & 0.98 & 2.3 & $\mathbf{1 6}$ & 2.29 \\
ECHAM5 & $\mathbf{0 . 3 3}$ & 0.99 & $\mathbf{1 . 5}$ & $\mathbf{1 5}$ & 2.37 \\
CSIRO-mk3.0, run1 & 0.55 & 0.76 & 1.9 & 33 & $\mathbf{2 . 3 9}$ \\
CSIRO-mk3.5 & 0.56 & 0.88 & 2.4 & 36 & 2.24 \\
\hline Ensemble & & & & & $\mathbf{3 . 3 4}$ \\
\hline
\end{tabular}

(a)

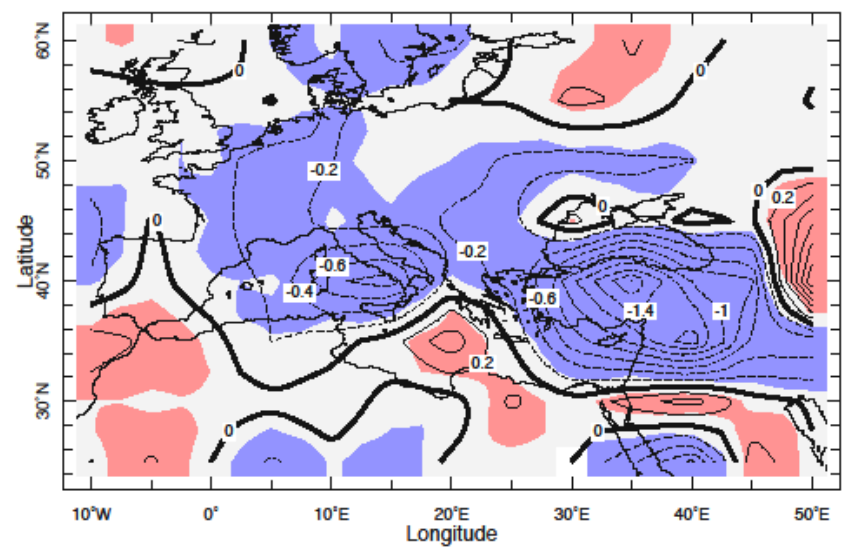

(b)

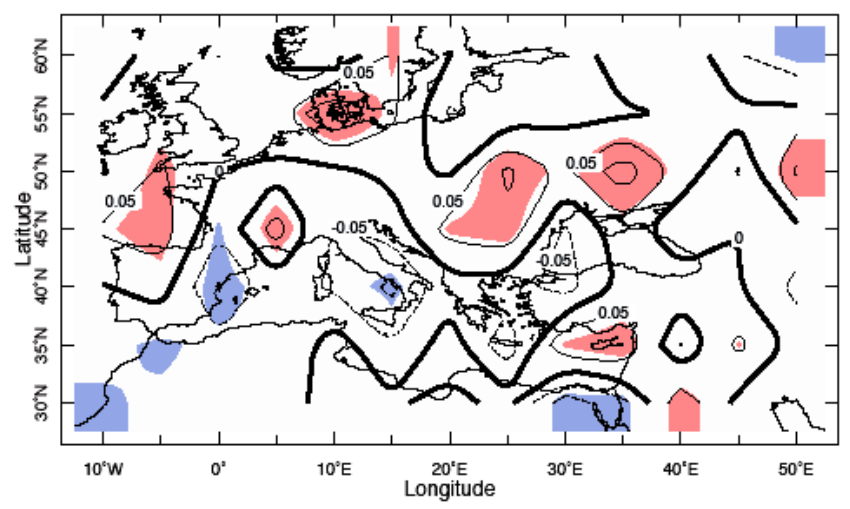

Fig. 4. Long-term trend in cyclone counts for DJF (in units of percentage per $10 \mathrm{yr}$ ) of (a) observations and (b) average of the 9 study models. The sign and significance of the trend is represented as in Fig. 3b.

\subsection{Inter-annual variations in the occurrence of Mediterranean cyclones}

The inter-annual standard deviation (STD) of MC occurrence for DJF was calculated for the large MB. The centers of large variability (not shown) in both observations and simulations coincide with the maxima of cyclone occurrence in the MB shown in Figs. 2 and 3a, respectively. Here we refer to the "relative STD", i.e. the STD divided by the local cyclone long-term mean occurrences. The relative STD for both observations and that averaged over the 9 study models is homogeneous (not shown). A comparison between the observed and simulated distributions indicates that the models slightly underestimate the relative year-to-year variations. The observed average relative STD is 1.2. It measures slightly below 1.0 over the majority of the Mediterranean Sea, but exceeds this value over western North Africa, Western Europe, the Iberian Peninsula and the Middle East. The average relative STD of the models is 0.95 and the values over most of Europe, the Mediterranean and the Middle East are lower than that, with values as low as 0.6. The local maximum over western North Africa is overestimated by the models.

The relative STD of each of the individual models, averaged over the larger $\mathrm{MB}$, are lower than that observed (Table 3), varying between 0.76 (CSIRO-mk3.0) and 1.08 (GFDL-cm2.0). An inspection of the distributions of the relative STD of the individual models shows that all of them capture the maximum over western North Africa, each of them show some weak signatures of high values over the Iberian peninsula and West Europe, but none of them show any maximum over the EM.

As part of the analysis of inter-annual variability, we also calculated the long-term trend in cyclone occurrence during the study period. Figure 4a shows the observed long-term trend for the large MB. The MB is dominated by decreasing 
trend (in agreement with Trigo et al., 2000) with two distinct extremes ( 0.95 significant): the major one over the eastern Turkey, with an extension toward the Balkan, and a secondary one over Italy. The simulated trend based on the individual models show non-significant patterns, with amplitudes considerably smaller than those found in observations and without having any spatially consistent structure. The multi-model average trend distribution (Fig. 4b) is weak and lacks the large center of negative trend in eastern Turkey and the opposite sign trend in western North Africa. However, 6 of the models (CSIRO-mk3.0, CSIRO-mk3.5, GFDL-cm2.0, GFDL-cm2.1, MIROC3 HiRes and INGV ECHAM 4) show footprints of negative trend in parts of the MB. In spite of the general failure in the collective models' ability to reproduce the observed long-term trend, it should be stressed that none of them showed a positive trend in MC occurrences.

\subsection{Long-term mean sea level pressure}

In an effort to relate the cyclone occurrence to the large-scale circulation, we compared the seasonal mean slp field in observations to that simulated in the models. Figure 5 shows the observed long-term DJF mean slp during the study period. The prominent features are the subtropical high-pressure region extending from the Atlantic into the Iberian Peninsula and North Africa and the south-to-north pressure gradient between the western Mediterranean (and the Alboran Sea) and the northeastern Atlantic, west of Ireland. Also prominent is the high-pressure over Siberia (the Siberian High), which is a baroclinic phenomenon, associated with the cold surface temperatures during winter (e.g. Cohen et al., 2001). Along the southern edge of the domain is the northern edge of the tropical low-pressure trough over sub-Saharan Africa. In the center of the domain there is a low-pressure region, stretching between the Atlantic and the Siberian Highs. This lowpressure region displays two secondary centers: a relatively strong one between the Italian Peninsula and Sardinia and a weaker center southwest of the Anatolian Peninsula, between Turkey and Crete. These two centers are consistent with the centers of MC density in Fig. 2. Thus this low pressure appears to be the footprint of MCs as they form and migrate eastward in the MB.

Figure 6 shows the long-term DJF mean slp for each of the study models. All of them display the high-pressure system to the south of the Mediterranean Sea, over North Africa and low pressure to the north, which is centered over the British Isles and extends into Europe. A comparison between the models and observations (Fig. 6) indicates a consistent model overestimate of the strength of the high-pressure zone over North Africa and the related south-to-north pressure gradient over southwestern Europe. Such overestimation was also noted by Stephenson et al. (2006) for the NAO simulated by the CMIP2 coupled models and by Raible et al. (2010) for the simulation of the ECHAM5 latest version. Moreover, the simulated low-pressure signature of MCs in each

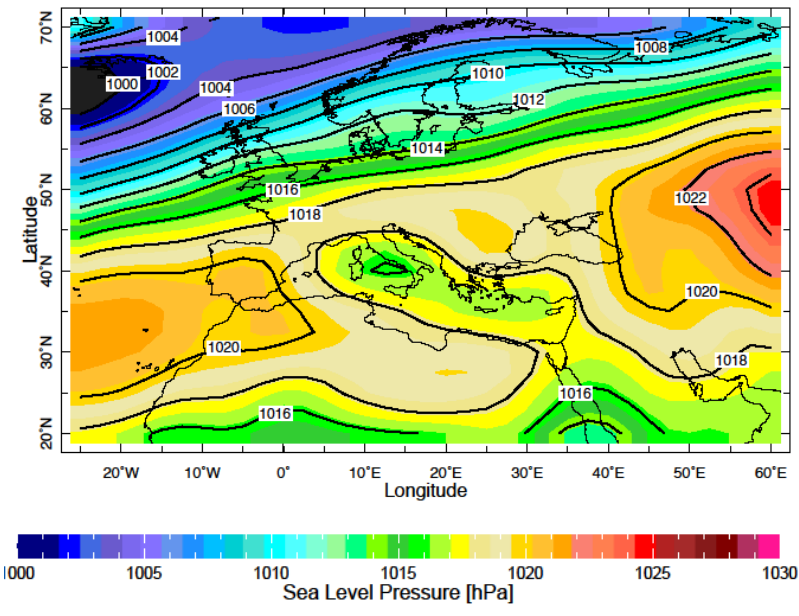

Fig. 5. Long-term mean sea level pressure for DJF based on the observations, in $\mathrm{hPa}$.

of them is weaker than in observations or completely missing. It is visible only in the maps of three of the models: the MIROC3 HiRes, the ECHAM5 and, somewhat less clearly, the ECHAM4. Note that these three models had also the smallest standard error in the cyclone density distributions. These two latter findings support the interpretation of the Mediterranean low-pressure trough as the footprint of MCs.

Since the ability of the models to resolve MCs had been examined through the cyclone distribution pattern (Sect. 4.1), we used the slp long-term means only for evaluating the models' reliability to represent the south-north pressure gradient in the western part of the domain. This was done by calculating the pressure difference between the average over the domain $30^{\circ} \mathrm{N}-35^{\circ} \mathrm{N}$ and $10^{\circ} \mathrm{W}-40^{\circ} \mathrm{E}$ and that in the domain $55^{\circ} \mathrm{N}-60^{\circ} \mathrm{N}$ and $10^{\circ} \mathrm{W}-40^{\circ} \mathrm{E}$. Based on this difference we defined a "south-north pressure index" (SNI) for each model as the ratio between the south-north pressure difference between the two domains in the pertinent model and that in observations. The corresponding values are displayed in the individual maps in Fig. 6. All of them exceed 1.0, reflecting the collective models' consistent overestimation of the south-north pressure-gradient. The values vary between 1.5 (for ECHAM5) and 3.65 (for the NCAR ccsm 3.0), with an average of 2.15. The 3 models with the lowest bias are the MIROC3 HiRes, ECHAM 5 and GFDL-cm2.0.

This slp collective models' biases are not confined to our study region. Figure 7 displays the spatial distribution of simulated vs. observed slp difference over the Northern Hemisphere between $10^{\circ} \mathrm{N}$ and $80^{\circ} \mathrm{N}$. The figure indicates a consistent negative bias in the mid-latitudes, being the largest over Siberia $(-8 \mathrm{hPa})$, in Alaska and the northeastern $\mathrm{Pa}-$ cific ( $-6 \mathrm{hPa}$ in both). This minimum is straddled by positive biases over the Arctic $(+8 \mathrm{hPa})$ and over North Africa and the Mediterranean $(+4 \mathrm{hPa})$. These biases are not widely discussed in the literature. However, resolving them is beyond the scope of this study. 

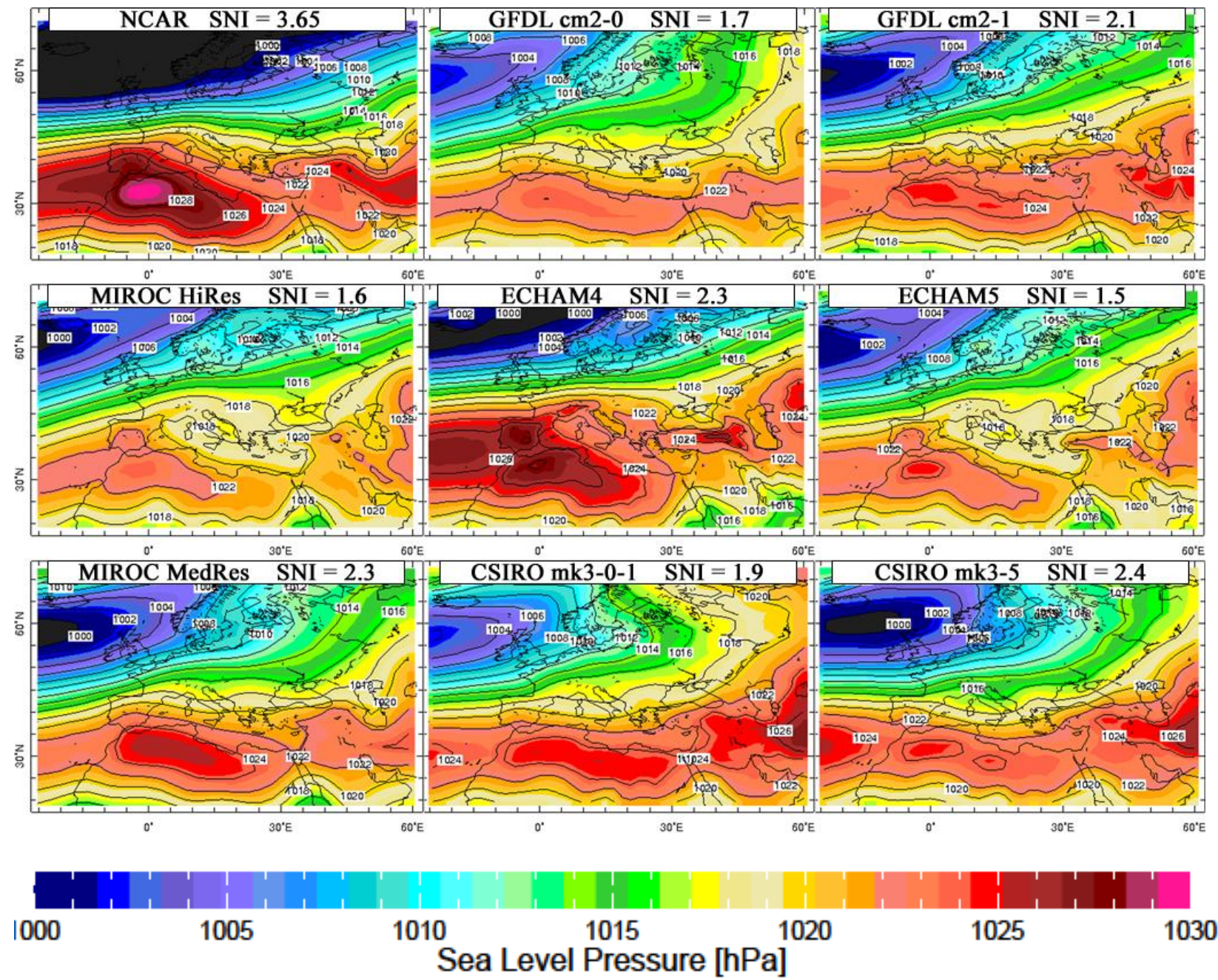

Fig. 6. As in Fig. 5, but for the 9 study models. The names of the individual models and their corresponding south-north pressure-difference index (SNI) are denoted above the respective panels.

\subsection{Long-term mean 500-hPa gph}

The simulated and observed long-term mean 500-hPa gph were compared as well. The average gph (contours) and geostrophic relative vorticity (colors) in the observations and models are shown in Fig. 8a and b, respectively. The geostrophic vorticity is used as an approximation for the vorticity due to absence of wind data in the model database. In the observations, a ridge is seen extending from the subtropical east Atlantic toward the British Isles and a trough extends from Eastern Europe toward the Balkan and the eastern half of the Mediterranean. The vorticity field is consistent with the gph field and emphasizes these features. The ridge west of Europe is accompanied by negative values, on the order of $-1 \times 10^{-5} \mathrm{~s}^{-1}$, and the trough over the EM is accompanied by maximum of $+1 \times 10^{-5} \mathrm{~s}^{-1}$. In the respective simulated fields (Fig. 8b), the ridge is shifted eastward and extends over the Iberian Peninsula and the trough is weak, with maximum relative vorticity of only half that of the observations $\left(\sim+0.5 \times 10^{-5} \mathrm{~s}^{-1}\right)$. The bias of the models is further demonstrated by the gph differences between them and the observations (Fig. 8c), being positive along the $30^{\circ} \mathrm{N}$ latitude, i.e. along the southern coasts of the Mediterranean (in agreement with the ECHAM5 simulation done by Raible et al. (2010), with a maximum of $30 \mathrm{~m}$ at $12^{\circ} \mathrm{E}$, and negative along $55^{\circ} \mathrm{N}$ latitude, with a maximum of $-75 \mathrm{~m}$ at $8^{\circ} \mathrm{W}$. The magnitude of each of these extrema is larger than the observed inter-annual standard deviation at the pertinent locations, implying that the biases are statistically significant. This feature indicates a common tendency among the models to have an anticyclonic bias in the upper-level flow over the $\mathrm{MB}$, expressed in a negative bias in the relative vorticity of $1 \times 10^{-5} \mathrm{~s}^{-1}$ over Italy and Greece. This is consistent with the collective models' tendency to underestimate the frequency of MCs. In order to better resolve the regional 

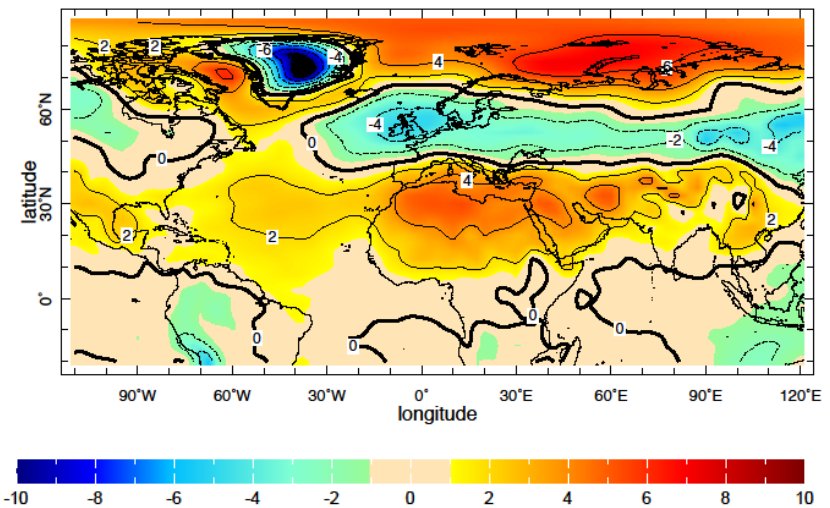

Fig. 7. DJF long-term mean sea level pressure difference (in $\mathrm{hPa}$ units) between the simulations and observations for the Northern Hemisphere.

specific features and to eliminate the zonally oriented biases, we calculated the standard error of each model with respect to observation in the geopotential zonal eddy (deviation from hemispheric zonal average; see Table 3). As is the case with their simulation of cyclone distribution, the ECHAM4, ECHAM5 and MIROC3 (HiRes) models show the smallest error, about half that of that for the other models.

\subsection{Inter-annual variations in the large-scale circulation}

The 5 spatial patterns (rotated EOFs; see Sect. 3.3) based on observations explain $88.8 \%$ of the inter-annual variance of the 500-hPa gph. The rotated model patterns were paired with their observed counterparts through visual comparison and confirmed by calculating spatial correlation between pairs. The average correlations between the pairs of rotated EOFs for the individual models varied between 0.63 (MIROC3 HiRes) and 0.79 (GFDL-cm2.1). The performance of the models in reproducing the observed rotated EOFs was estimated by the degree of similarity between the respective patterns, determined as the ratio between the average spatial correlations between the 5 pairs of EOFs found most correlated and that of the other 20 pairs (see Table 3). The models showing the highest performance are MIROC 3 MedRes, GFDL-cm2.0 and CSIRO-mk3.0.

The collective ability of the models to simulate the observed patterns (described in Sect. 3.3) is demonstrated in Fig. 9, which compares the 5 rotated EOFs derived from the multi-model sample (right panel) to the observations (left panel). The fit between the patterns, as reflected by spatial correlation, is better than those found for any individual model. The four leading patterns (in terms of percent variance explained) spatially correlate with their observed counterpart at a level of 0.86 and above, and the average for the 5 rotated EOFs is 0.83 - also above those of the individual models. The rotated 1st EOF pattern of both observations and (a)

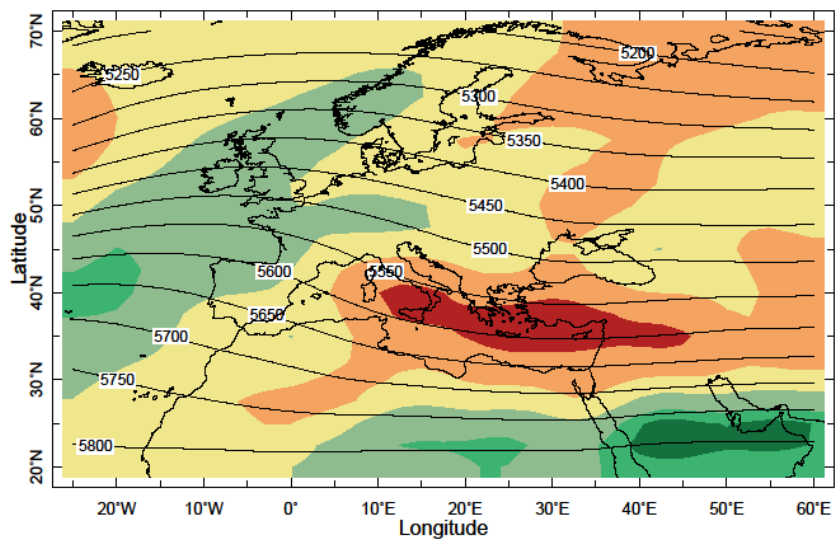

(b)

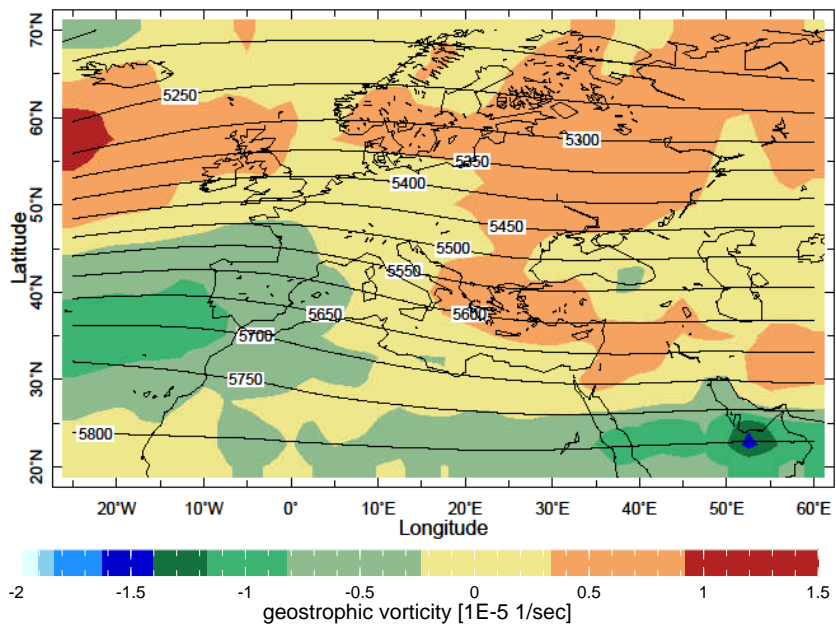

(c)

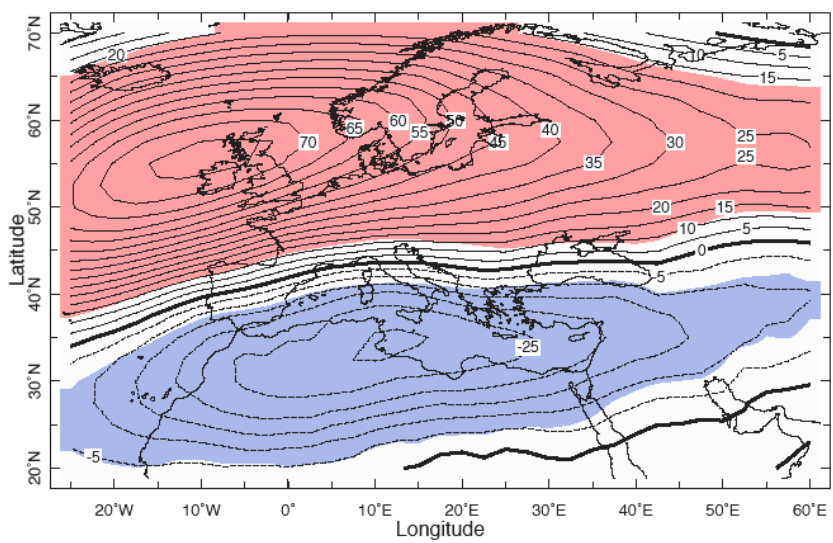

Fig. 8. Long-term mean gph for DJF (contours, in meters) and geostrophic relative vorticity (in $10^{-5} \mathrm{~s}^{-1}$ units, shaded), both at $500-\mathrm{hPa}$, for (a) observations and (b) simulations. (c) The $500 \mathrm{hPa}$ gph difference between them (b-a). The sign and significance of the trend is represented as in Fig. 3b. 


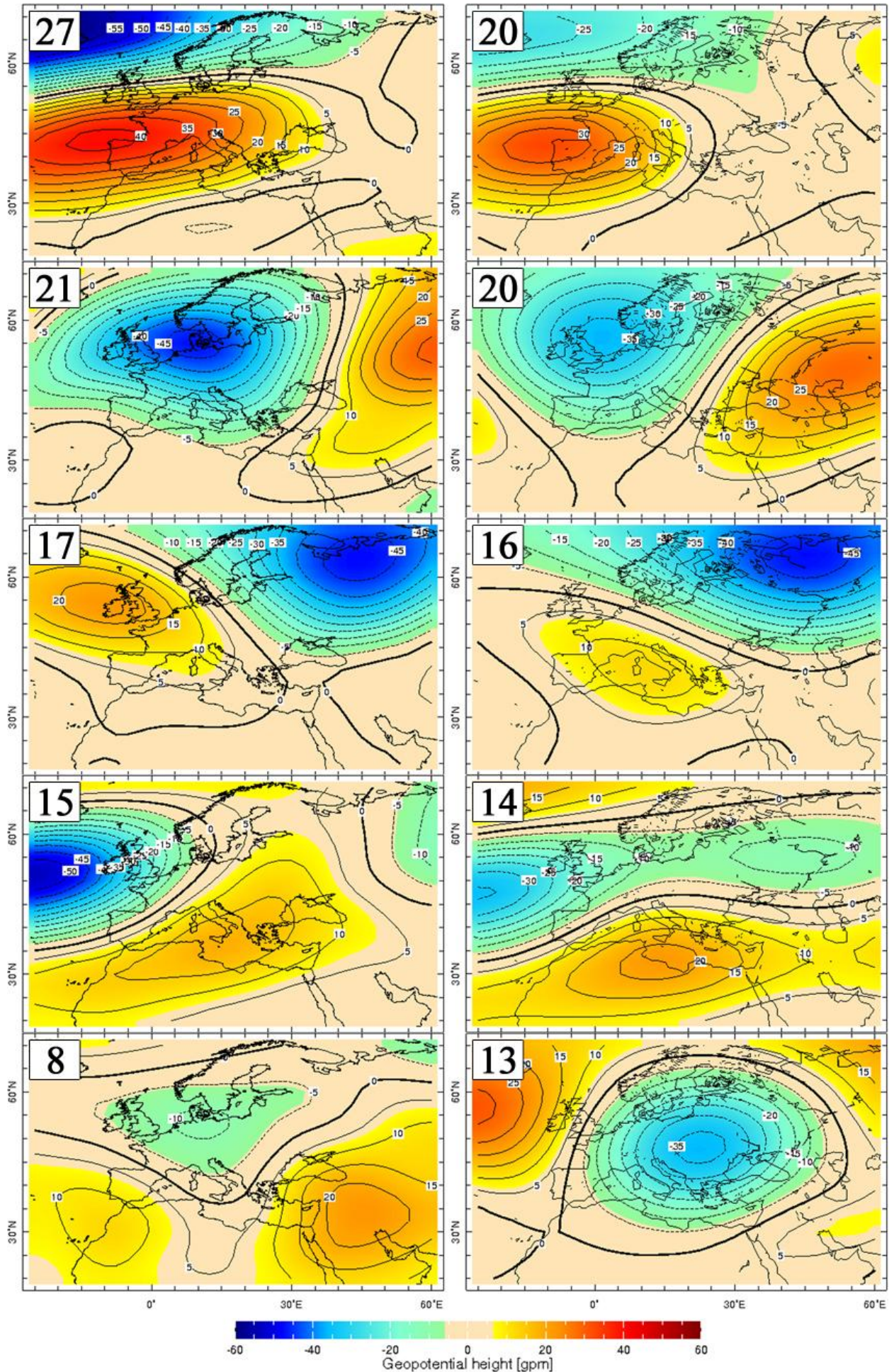

Fig. 9. Varimax rotated EOFs of $500 \mathrm{hPa}$ gph, derived from observations (left panels) and the ensemble of all the 9 study models (right panels) calculated by pooling them together. The numbers denote the percentage of the variance explained by the pertinent EOF. The patterns are paired according to the spatial correlation between them. 
simulations resemble the NAO pattern, which is considered as the dominant for the study region and was found to be well captured by the models included in CMIP1 (Stephenson and Pavan, 2003) and CMIP2 (Stephenson et al., 2006). The 5 th rotated EOFs, which have the lowest variance explained, exhibit a rather low spatial correlation of 0.35 . It should be noted that the 5 rotated EOFs extracted from the models explain $83.2 \%$ of the inter-annual variance of the 500-hPa gph. The same experiment was done for the slp field and yielded similar and consistent results, so they are not shown here.

\section{Summary and discussion}

This study aims to evaluate the ability of global coupled climate models to reproduce the climatological synoptic regime of the Mediterranean Basin. The emphasis is given to the MCs because of their crucial role in the regional hydrology and the consequence to society (e.g. Iglesias et al., 2007). The quality of the simulation of MC distribution in space is thus critical for the collective models' ability to reliably project the hydrological future of the region. In accordance with this goal the output of 9 CMIP3 models are compared to the NCEP-NCAR reanalyzed data, and inter-compared in terms of temporal and spatial distribution of synoptic features over Europe and the Mediterranean region.

In all models, a maximum in MC density and a Mediterranean upper-level trough appear in similar locations as in observations. The models also simulate reasonably well the inter-annual variation in the occurrence of MCs. Also important in the context of this study is that the main large-scale patterns of inter-annual variability, as represented by rotated EOFs of the seasonal (wintertime) mean slp and $500 \mathrm{hPa}$ gph anomalies, are well simulated by the models. In this respect, the collective estimate based on all the models resembles the observations better than does each model separately.

However, the models as a whole underestimate the observed level of Mediterranean cyclone density. This discrepancy is largest in the Western Basin, where the simulated winter average cyclone count is about $60 \%$ of that observed, but is also noted in its Eastern part. Another discrepancy found is their inability to reproduce the observed decreasing trend in MCs, especially in the eastern part.

The inter-comparison shows that models which are closer to observations in terms of a single measure, e.g. cyclone density distribution, do not necessarily perform better in all measures. For MCs detection and reproducing the mean $500 \mathrm{hPa}$ gph field, MIROC3 HiRes, ECHAM 5, and ECHAM 4 agree best with observations; for reconstructing the south-to-north pressure gradient over West Europe it is MIROC3 HiRes, ECHAM 5, and GFDL-cm2.0 that agree best with observations; for reproducing the inter-annual variation in cyclone occurrence, GFDL-cm2.0, NCAR ccsm3.0, and GFDL-cm2.1 agree best with the observation; and for identifying properly the dominating large-scale patterns
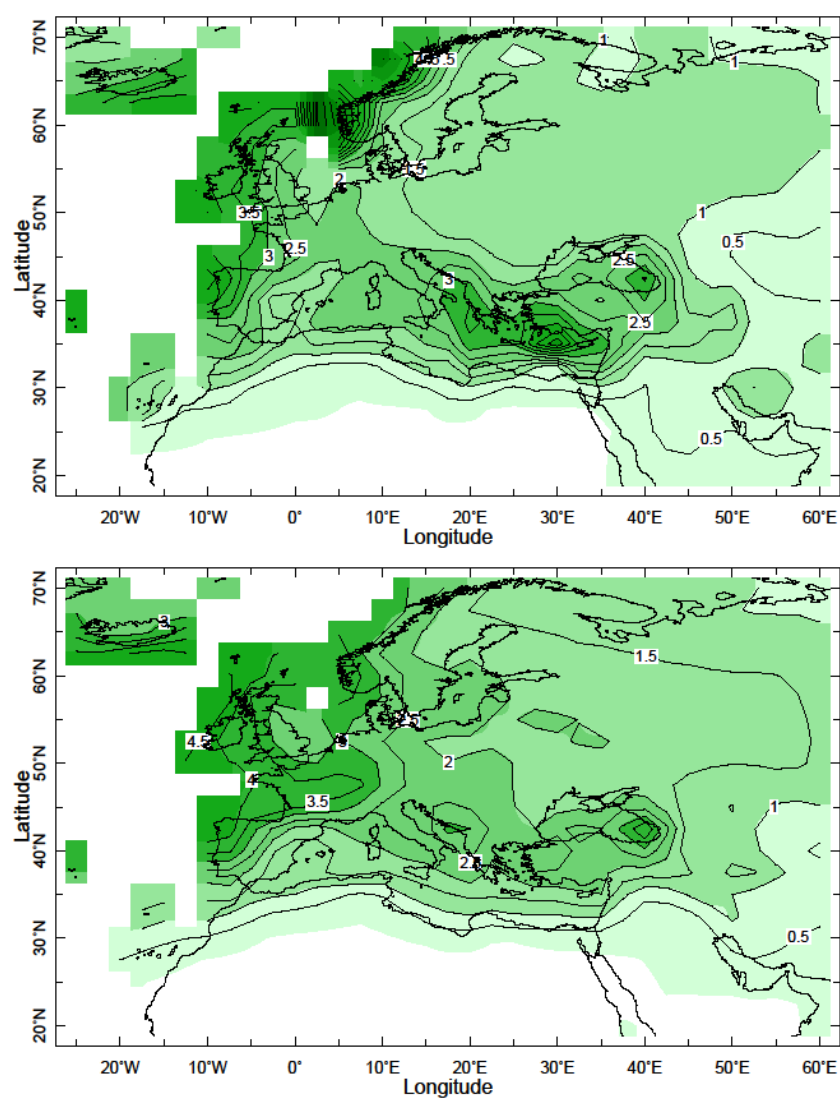

(c)

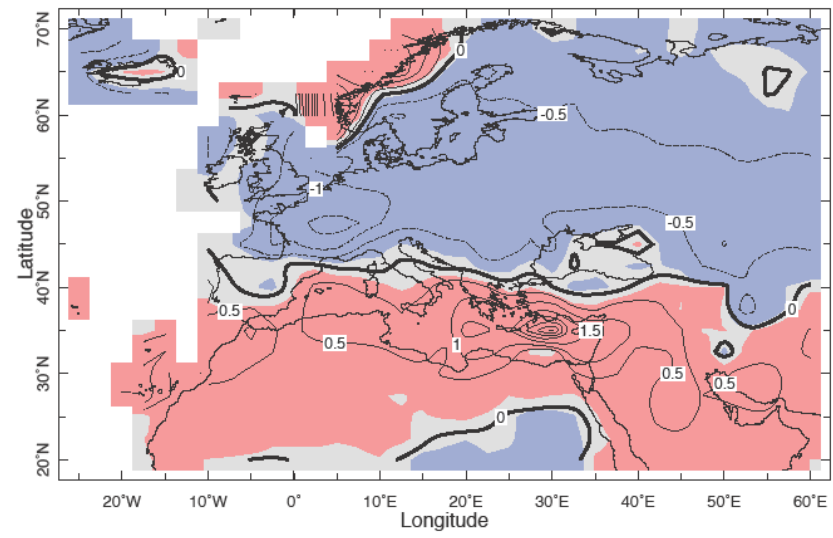

Fig. 10. Long-term mean of the DJF precipitation according to observation (a), taken from the NOAA/NCEP CAMS data set (Ropelewski et al., 1984, Janowiak and Xie, 1999), the 9 study models (b) and difference between them (c), in $\mathrm{mm} \mathrm{day}^{-1}$ units. The resolution of the observed precipitation is $2^{\circ} \times 2^{\circ}$. The sign and significance of the trend is represented as in Fig. $3 \mathrm{~b}$.

(represented by the rotated EOFs) the closest to observations are the MIROC3 MedRes, GFDL-cm2.1, and CSIRO-mk3.0.

The high temporal correlation between precipitation in the MCs discussed in Sect. 1 and the deviations of simulated cyclone density from that observed suggest that the 
precipitation will be also underestimated over the MB and overestimated over Europe. Figure 10 shows the observed and simulated (by the 9 study models) long-term mean precipitation for DJF and the differences between them. The models reproduce quite realistically the distribution pattern, i.e. the maximum along the northern Mediterranean coasts. But, indeed, there is a substantial underestimation of the Mediterranean precipitation and overestimation over the majority of Europe, both in the order of $30 \%$. The difference between the modeled and observed rainfall exceeds considerably the inter-annual standard deviation (not shown), so it can be considered statistically significant.

Consistent with the underestimation of cyclone density, we found discrepancy in the mean related cyclonic system over the Mediterranean both in the slp and mid-tropospheric gph fields, a noticeably stronger subtropical high-pressure along North Africa, extending northward over the MB. This bias is accompanied by an overestimation of the south-to-north pressure gradient over Western Europe, about twice that observed. The standard error in cyclone distribution and that in the 500-hPa gph of the study models were found highly correlated $(R=0.74)$, presumably due to the deep vertical extent of MCs (e.g. Tsidulko and Alpert, 2001). The correlation between standard error in cyclone distribution and the NSI (reflecting the south-to-north pressure gradient) was found to be 0.32. In spite of its marginal significance, this suggests that the formation of MCs might be suppressed under enhanced westerlies over Western Europe (as implied by the enhanced zonal pressure-gradient when the NAO is in its positive phase, Hurrell et al., 2003). Further analysis and perhaps idealized model simulations are needed to determine cause and effect between these discrepancies: cyclonic activity on the one hand and mean circulation bias on the other. It is notable, however, that synoptic activity and large scale circulation anomalies are inter-linked in a dynamical relationship and thus possibly both discrepancies may be tied to the inability of the models to simulate the geographical details of the MB due mainly to their low spatial resolution. Support for this assertion is provided by the fact that the models that offer a better simulation of cyclone counts, the MIROC3 HiRes, ECHAM 5 and ECHAM 4, also have relatively high horizontal and vertical resolution. These 3 models also display a smaller bias in the simulation of the mean $500 \mathrm{hPa}$ fields (see Table 3).

The relationship between the models' characteristics and their ability to reproduce the cyclone distribution is demonstrated through scatter plots of their standard error in cyclone density distribution and their horizontal and vertical resolution (Fig. 11a and b, respectively, Tables 1 and 3). The scatter plots indicate that the models reconstructing better the observed cyclone density distribution are those having larger number of vertical levels and finer horizontal resolution. A better methodology for examining the relationship between a model's resolution and performance is to compare the output of several versions of the same model with varying
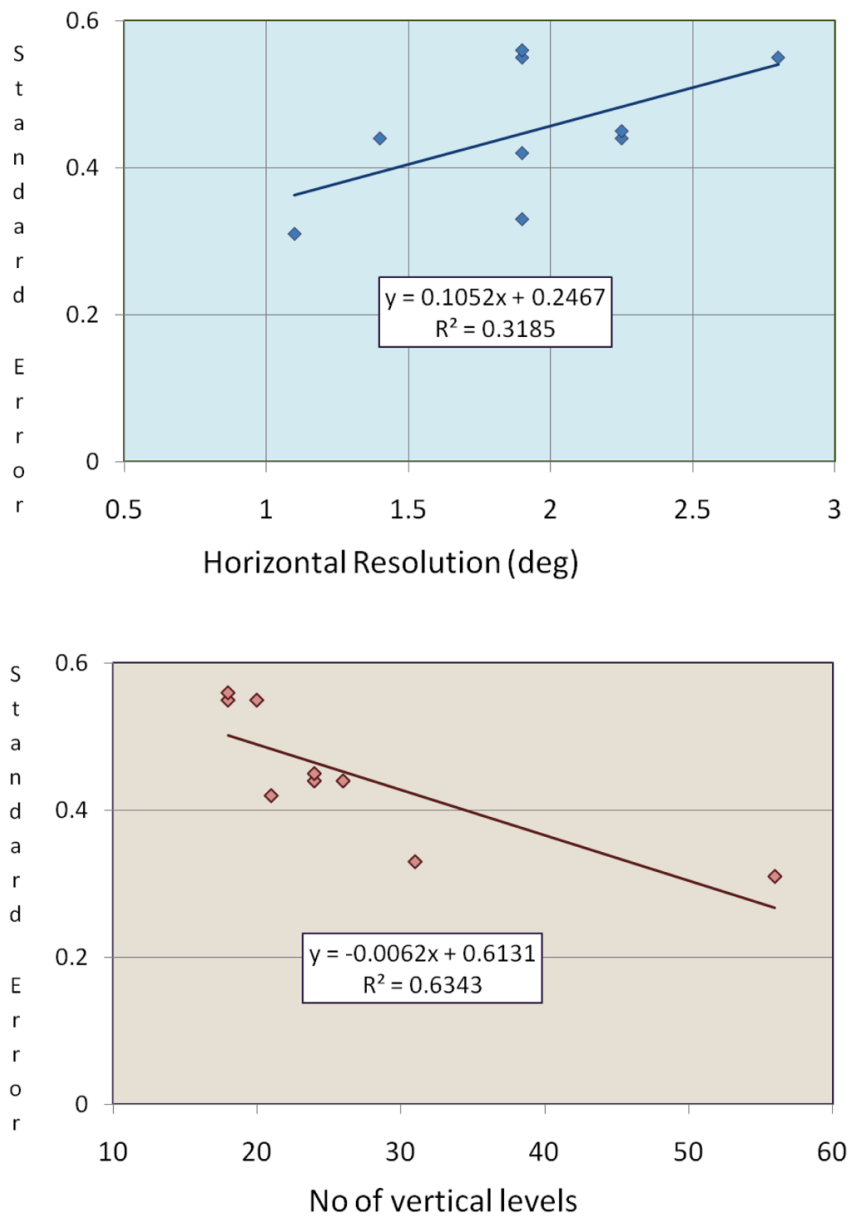

Fig. 11. scatter plots of the standard error (with respect to observation) of the study models in reconstructing the cyclone density distribution and their horizontal (a) and vertical resolution (b).

resolution. Unfortunately, we have here only one example for that, i.e., the two versions of the MIROC3 GCM, in which the one with higher resolution capture MCs much better than its counterpart. Our results concerning the vertical resolution are consistent with Roeckner et al. (2006), who showed that vertical resolution is crucial for simulating baroclinic eddies. They also claimed that increased vertical resolution has to be followed by an increase in horizontal resolution for consistency. It seems that additional factors related to the vertical spacing, such as partition of the vertical levels and the number of levels within the boundary layer, can be important. Finer vertical resolution allows more accurate representation of the complexity of topography, which plays a key role in the Mediterranean cyclogenesis. It is interesting to note that the model spatial resolution was not found significantly correlated with the overall number of cyclones in the study area (compare Tables 1 and 2 and see discussion in Sect. 4.1).

Another feature that needs further elaboration is the inability of the models to reproduce the negative trend observed in MCs. The observed trend may reflect the beginning of the 
expected reduction of MCs due to global warming (IPCC, 2007) or just a natural internal climatic variation, which cannot be captured by climate models. Indeed, the observed trend is attributed to the increasing trend in the NAO (Hurrell et al., 2003), whatever its source is. The same trend was found in the time series of the observed rotated EOF \#1, which resembles the NAO (see Fig. 9). Analysis done for the simulated rotated EOFs of each model that resembles the observed rotated EOF\#1 did not show any consistent trend. In four of the 9 models the trend was negative; in 3 - positive and in the remaining 2 - no trend. Consistently with the above, the long-term trend of the $500 \mathrm{hPa}$ gph (Lu et al., 2004, Fig. 1a) shows clearly the large-scale background for the decreasing trend in Mediterranean cyclonic activity, as reflected by the anti-cyclonic trend expressed in the negative values of the relative vorticity.

The relation found here between the degree of the underestimation of MCs population by the models and their resolution suggests that the refinement in the more advanced climate models is promising for their ability to better simulate the Mediterranean cyclogenesis, and to predict the Mediterranean Basin's response of to future climatic changes.

Acknowledgements. Support for B. Ziv came from the Israeli Science Foundation (ISF grant No. 764/06 and 108/10) and from the Research Authority of the Open University of Israel. A kind travel grant from the Lamont-Doherty Earth Observatory Climate Center in support of B. Ziv's stay at Lamont during the research stage is also acknowledged. The Lamont co-authors: Y. Kushnir, N. Naik, and J. Nakamura were supported under an amendment to the NOAA cooperative agreement for the Cooperative Institute for Climate Applications and Research (CICAR), grants NA08OAR4320754 and NA06OAR4310143. We thank R. Seager, M. Ting, and M. Cane for helpful discussions. This is LDEO publication number 7676 .

Edited by: S. Davolio

Reviewed by: three anonymous referees

\section{References}

Alpert, P. and Ziv, B.: The Sharav Cyclone: observations and some theoretical considerations, J. Geophys. Res., 94, 18495-18514, 1989.

Alpert, P., Tsidulko, M., Krichak, S., and Stein, U.: A multi-stage evolution of an ALPEX cyclone, Tellus, 48A, 209-220, 1996.

Barnett, T. P.: Comparison of near-surface air temperature variability in 11 coupled global climate models, J. Climate, 12, 511-518, 1999.

Bengtsson, L., Hodges, K., and Roeckner, E.: Storm tracks and climate change, J. Climate, 19, 3518-3543, 2006.

Blender, R. and Schubert, M.: Cyclone Tracking in Different Spatial and Temporal Resolutions, Mon. Weather Rev., 128, 377-384, 2000.
Cheng, X., Nitsche, G., and Wallace, J. M.: Robustness of lowfrequency circulation patterns derived from EOF and rotated EOF analysis, J. Climate, 8, 1709-1713, 1995.

Cohen, J., Saito, K., and Entekhabi, D.: The role of the Siberian high in Northern Hemisphere climate variability, Geophys. Res. Lett., 28, 299-302, 2001.

Dunkeloh, A. and Jacobeit, J.: Circulation dynamic of Mediterranean variability 1948-98, Int. J. Clim., 23, 1843-1866, 2003.

Frich, P., Alexander, L. V., Della-Marta, P., Gleason, B., Haylock, M., Klein Tank, A. M. G., and Peterson, T.: Observed coherent changes in climatic extremes during the second half of the twentieth century, Clim. Res., 19, 193-212, 2002.

Giorgi, F. and Lionello, P.: Climate change progections for the Mediterranean region, Glob. Climate Change, 63, 90-104, doi:10.1016/j.gloplacha.2007.09.005, 2008.

Hertig, E. and Jacobeit, J.: Assessments of Mediterranean precipitation changes for the 21 st century using statistical downscaling techniques, Int. J. Clim., 28, 1025-1045, 2008.

Hurrell, J. W., Kushnir, Y., Ottersen, G., and Visbeck, M.: An overview of the North Atlantic Oscillation, in: The North Atlantic Oscillation: Climatic Significance and Environmental Impact, edited by: Hurrell, J. W., Kushnir, Y., Ottersen, G., and Visbeck, M., American Geophysical Union, Geophysical Monograph Series, Washington DC, 1-35, 2003.

Iglesias, A., Garrote, L., Flores, L., and Moneo, M.: Challenges to manage the risk of water scarcity and climate change in the Mediterranean, Water Resour. Manage., 21, 775-788, 2007.

IPCC: The physical science basis, in: Contribution of working group I to the fourth assessment report of the intergovernmental panel on climate change, Cambridge University Press, Cambridge, 976 pp., 2007.

Jacobeit, J.: Variations of trough positions and precipitation patterns in the Mediterranean area, Int. J. Clim., 7, 453-476, 1987.

Janowiak, J. E. and Xie, P.: CAMS_OPI: a global satellite-raingauge merged product for real-time precipitation monitoring applications, J. Climate, 12, 3335-3342, 1999.

Kalnay, E., Kanamitsu, M., Kistler, R,, Collins, W., Deaven, D., Gandin, L., Iredell, M., Saha, S., White, Goollen, J., Zhu, Y., Chelliah, M., Ebisuzaki, W., Higgins, W., Janowiak, J., Mo, K. C., Ropelewski, C., Wang, J., Leetmaa, A., Reynolds, R., Jenne, R., and Joseph, D.: The NCEP-NCAR 40-year reanalysis project, B. Am. Meteorol. Soc., 77, 437-471, 1996.

Kistler, R., Kalnay, E., Collins, W., Saha, S., White, G., Woollen, J., Chelliah, M., Ebisuzaki, W., Kanamitsu, M., Kousky, V., Van Den Dool, H., Jenne, R., and Fiorino, M.: The NCEP-NCAR 50year reanalysis: monthly means CD-ROM and documentation, B. Am. Meteorol. Soc., 82, 247-267, 2001.

Kouroutzoglou, J., Flocas, H. A., Simmonds, I., Keay, K., and Hatzaki, M.: Assessing characteristics of Mediterranean explosive cyclones for different data resolution, Theor. Appl. Clim., 105, 263-275, 2011.

Lionello, P. (Ed.): The Climate of the Mediterranean Region, from the past to the future, 1st Edn., Elsevier, 2012.

Lionello, P. and Giorgi, F.: Winter precipitation and cyclones in the Mediterranean region: future climate scenarios in a regional simulation, Adv. Geosci., 12, 153-158, doi:10.5194/adgeo-12-1532007, 2007.

Lionello, P., Dalan, F., and Elvini, E.: Cyclones in the Mediterranean region: the present and the doubled $\mathrm{CO}_{2}$ climate scenar- 
ios, Clim. Res., 22, 147-159, 2002.

Lionello, P., Malanbotte-Rizzoli, P., and Boscolo, R. (Eds.): Mediterranean climate variability. Developments in earth and environmental sciences, vol 4, Elsevier, Amsterdam, 2006.

Lu, J., Greatbatch, R. J., and Peterson, K. A.: Trend in Northern Hemisphere winter tmospheric circulation during the last half of the twentieth century, J. Climate, 17, 3745-3760, 2004.

Mariotti, A., Zeng, N., Yoon, J. H., Artale, V., Navarra, A., Alpert, P., and Li, L. Z. X.: Mediterranean water cycle changes: transition to drier 21 st century conditions in observations and CMIP3 simulations, Environ. Res. Lett., 3, 044001, doi:10.1088/17489326/3/4/044001, 2008.

Meehl, G. A., Covey, C., Delworth, T., Latif, M., McAvaney, B., Mitchell, J. F. B., Stouffer, R. J., and Taylor, K. E.: The WCRP CMIP3 multimodel dataset - A new era in climate change research, B. Am. Meteorol. Soc., 88, 1383-1394, 2007.

Nakicenovic, N. and Swart, R.: Special Report on Emissions Scenarios, Cambridge University Press, 599 pp., 2000.

North, G. R., Bell, T. L., Cahalan, R. F., and Moeng, F. J.: Sampling errors in the estimation of empirical orthogonal functions. Mon. Weather Rev., 110, 699-706, 1982.

Pinto, J. G., Spangeh, T., Ulbrich, U., and Speth, P.: Sensitivities of a cyclone detection and tracking algorithm: individual tracks and climatology, Meteorol. Z., 14, 823-838, 2005.

Preisendorfer, R. W.: Principal Component Analysis in Meteorology, Development Atmos. Sci., 17, 425 pp., 1988.

Raible, C. C.: On the relation between extremes of midlatitude cyclones and the atmospheric circulation using ERA40, Geophys. Res. Lett., 34, L07703, doi:10.1029/2006GL029084, 2007.

Raible, C. C. and Blender, R.: Midlatitude cyclonic variability in GCM- simulations with different ocean representations, Clim. Dynam., 22, 239-248, 2004.

Raible, C. C., Della-Marta, P., Schwierz, C., Wernli, H., and Blender, R.: Northern Hemisphere extratropical cyclones: a comparison of detection and tracking methods and different reanalyses, Mon. Weather Rev., 136, 880-897, 2008.

Raible, C. C., Ziv, B., Saaroni, H., and Wild, M.: Winter synopticscale variability over the Mediterranean Basin under future climate conditions as simulated by the ECHAM5, Clim. Dynam., 35, 473-488, 2010.

Randall, D. A., Wood, R. A., Bony, S., Colman, R., Fichefet, T., Fyfe, J., Kattsov, V., Pitman, A., Shukla, J., Srinivasan, J., Stouffer, R. J., Sumi, A., and Taylor, K. E.: Climate Models and Their Evaluation, in: Climate Change: The Physical Science Basis, Contribution of Working Group I to the Fourth Assessment Report of the Intergovernmental Panel on Climate Change, edited by: Solomon, S., Qin, D., Manning, M., Chen, Z., Marquis, M., Averyt, K. B., Tignor, M., and Miller, H. L., Cambridge University Press, Cambridge, UK and New York, NY, USA, 2007.
Reichler, T. and Kim, J.: How well do coupled models simulate today's climate, B. Am. Meteorol. Soc., 89, 303-311, 2008.

Roeckner, E., Brokopf, R., Esch, M., Giorgetta, M., Hagemann, S., Kornblueh, L., Manzini, E., Schlese, U., and Schulzweida, U.: Sensitivity of simulated climate to horizontal and vertical resolution in the ECHAM5 atmosphere model, J. Climate, 16, 3771-3791, 2006.

Romem, M., Ziv, B., and Saaroni, H.: Scenarios in the development of Mediterranean cyclones, Adv. Geosci., 12, 59-65, doi:10.5194/adgeo-12-59-2007, 2007.

Ropelewski, C. F., Janowiak, J. E., and Halpert, M. S.: The Climate Anomaly Monitoring System (CAMS). Climate Analysis Center, NWS, NOAA, Washington, DC, 39 pp., 1984.

Stephenson, D. B. and Pavan, V.: The North Atlantic Oscillation in coupled climate models: a CMIP1 evaluation, Clim. Dynam., 20, 381-399, 2003.

Stephenson, D. B., Pavan, V., Collins, M., Junge, M. M., Quadrelli, R. and participating CMIP2 modeling groups: North Atlantic Oscillation response to transient greenhouse gas forcing and the impact on European winter climate: a CMIP2 multi-model assessment, Clim. Dynam., 27, 401-420, 2006.

Tafferner, A. and Egger, J.: Test of Theories of Lee Cyclogenesis: ALPEX Cases, J. Atmos. Sci., 47, 2417-2428, 1989.

Trigo, I. F., Davies, T. D., and Biggs, G. R.: Decline in the Mediterranean rainfall caused by the weakening of the Mediterranean cyclones, Geophys. Res. Lett., 27, 2913-2916, 2000.

Trigo, I. F., Bigg, G. R., and Davis, T. D.: Climatology of cyclogenesis mechanisms in the Mediterranean, Mon. Weather Rev., 130, 549-569, 2002.

Tsidulko, M. and Alpert, P.: Synergism of upper-level potential vorticity and mountains in Genoa lee cyclogenesis - A numerical study, Meteor. Atmos. Phys., 78, 261-285, 2001.

Ulbrich, U., Leckebusch, G. C., and Pinto, J. G.: Extra-tropical cyclones in the present and future climate: a review, Theor. Appl. Clim., 96, 117-131, 2009.

Xoplaki, E., Gonzalez-Rouco, J. F., Luterbacher, J., and Wanner, H.: Wet season Mediterranean precipitation variability: influence of large-scale dynamics and trends, Clim. Dynam., 23, 63-78, 2004.

Zolina, O. and Gulev, S. K.: Improving the Accuracy of Mapping Cyclone Numbers and Frequencies, Mon. Weather Rev., 130, 748-759, 2002. 